\title{
Influence of Delayed Pours of Addition Silicone Impressions on The Dimensional Accuracy of Casts
}

\author{
Mehta $\mathbf{R}^{1}$, Dahiya $\mathrm{A}^{2}$, Mahesh $\mathbf{G}^{3}$, Kumar $\mathrm{A}^{4}$, Wadhwa $\mathbf{S}^{5}$, Duggal $\mathbf{N}^{6}$, Pande $\mathbf{S}^{7}$
}

\begin{abstract}
Aims and objectives: To evaluate and compare the time dependent dimensional accuracy of polyvinyl siloxane impressions.

Materials and methods: A brass master die containing two identical posts simulating two complete crown tapered abutment preparation was served as a standardized master model. Impressions were made with polyvinyl siloxane materials (monophase and regular body) using a brass made custom tray. The impressions were poured at intervals of $75 \mathrm{~min}, 24$ hours, 48 hours and 1 week, Interabutment and intraabutment distance were measured in the recovered stone dies using a profile projector with an accuracy of $0.001 \mathrm{~mm}$.
\end{abstract}

Results: Results of this study indicated that the casts made were dimensionally accurate and the polyvinyl siloxane silicones are dimensionally stable impressions for one week period.

Conclusion: Delayed pouring of the impressions at four different time periods did not significantly affect the accuracy of the casts produced.

Keywords: Accuracy, Dimensional stability, Elastic recovery, Vinyl polysiloxane, Delayed pouring

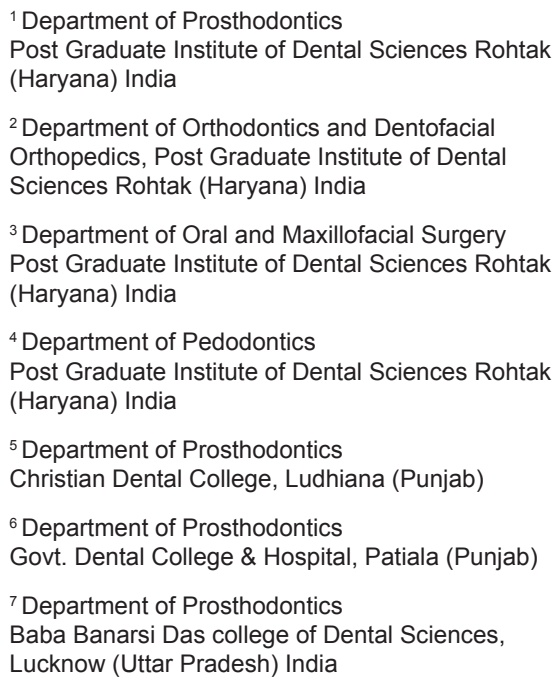

${ }^{2}$ Department of Orthodontics and Dentofacial Orthopedics, Post Graduate Institute of Dental Sciences Rohtak (Haryana) India

${ }^{3}$ Department of Oral and Maxillofacial Surgery Post Graduate Institute of Dental Sciences Rohtak (Haryana) India

${ }^{4}$ Department of Pedodontics

Post Graduate Institute of Dental Sciences Rohtak (Haryana) India

${ }^{5}$ Department of Prosthodontics Christian Dental College, Ludhiana (Punjab)

${ }^{6}$ Department of Prosthodontics

Govt. Dental College \& Hospital, Patiala (Punjab)

${ }^{7}$ Department of Prosthodontics

Baba Banarsi Das college of Dental Sciences, Lucknow (Uttar Pradesh) India

\section{Contact Author}

Dr. Amit Dahiya amitdahiya0909@gmail.coma

J Oral Health Comm Dent 2014;8(3)148-153

\section{INTRODUCTION}

$1 \sqrt{ }$ aking an impression represents a critical step in processing and fitting of a dental prosthesis. The definite impression should be accurate to fabricate restoration with ideal marginal fit, internal fit, interproximal contacts and occlusal contacts $(1,2)$. A variety of impression materials as silicones, polyether, polysulfide and alginate are available for crowns and fixed partial denture impressions. The addition-type silicone impression material i.e. polyvinyl siloxane is the most preferred material in the field of prosthodontics due to its favorable qualities, relative simplicity and reliability $(3,4)$.

The accuracy and functional efficiency of prosthesis depends on an accurate impression which is reproduced on a gypsum cast. The exact moment of pouring die stone into the impression is one of the factors affecting precision of dental cast (5). Polyvinyl siloxane impression material may exhibit dimensional changes with delay in pouring due to continuing polymerization of the impression material, elastic recovery and relaxation of stresses. As the impression has to be sent to the laboratory where the dentist loses control of when the impression is poured, an impression material should remain dimensionally accurate for that time period. Delay in pouring of impression gives operator sufficient time to perform various chair side procedures and impression can be poured at the convenience of the operator over extended time period without undergoing distortion (6). Though the delay period allows both the release of volatile 
substances and the elastic recovery of the material, it should not be too long, otherwise distortion of the impression may occur (7). Stackhouse observed that the stone dies poured successively from the same elastomeric impressions became increasingly shorter in length and thicker in diameter (8). However Tjan et al found that the repouring and delayed pouring of the rubber base impressions did not affect their dimensional accuracy and stability (9).

Ali et al concluded that repouring of the impression up to seven days did not affect the dimensional accuracy of the resultant casts (7).

As the literature provided conflicting views regarding the time dependent accuracy of elastomeric impression materials, a study was undertaken to evaluate if delayed pouring of addition silicone impression materials would influence the dimensional accuracy of resultant casts.

\section{MATERIALS AND METHODS}

The study was conducted in the Department of Prosthodontics, Govt. dental college, Patiala, Punjab, for comparative evaluation of dimensional accuracy of casts made by delayed pouring of different viscosities of vinyl polysiloxane impressions using custom tray. The materials used were Monophase polyvinyl siloxane impression material (Aquasil, Caulk/Dentsply) and regular/medium bodied polyvinyl

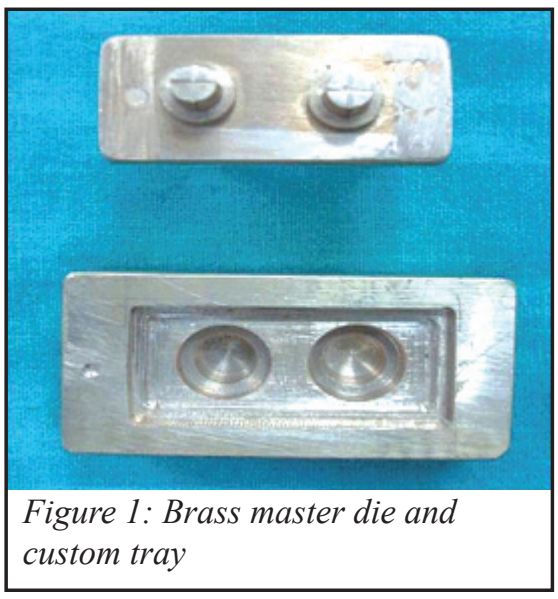

siloxane impression material (Reprosil, Caulk/Dentsply).

\section{Master model}

A brass master die of size $52 \times 24 \mathrm{~mm}$ containing two identical posts simulating two complete crown tapered abutment preparation was served as a standardized master model. The abutments were prepared with reference cross grooves on occlusal and proximal surfaces for reference measurements. (Figure 1) Reference measurements (made by profile projector with an accuracy of $0.001 \mathrm{~mm}$ or $1 \mathrm{um}$ ) of the standardized master model were as diameter of each post- $6-25 \mathrm{~mm}$. height of each post $-6-25 \mathrm{~mm}$, interabutment distance between each post $-21-5 \mathrm{~mm}$ (Figure 2).

\section{Custom tray and model index fabrication}

A specially prepared brass custom tray having a uniform space of approximately $2 \mathrm{~mm}$ for the addition silicone impression material was fabricated for making the impressions. An index was made for precise seating and stabilization of the master die during impression making. The whole assembly was further stabilized on the die stone slab for precise positioning. (Figure 3).

\section{Impression making}

To simulate oral environment, master die was maintained at $370 \mathrm{C}$ in the oven. A thin even coat of tray adhesive was applied on the custom tray

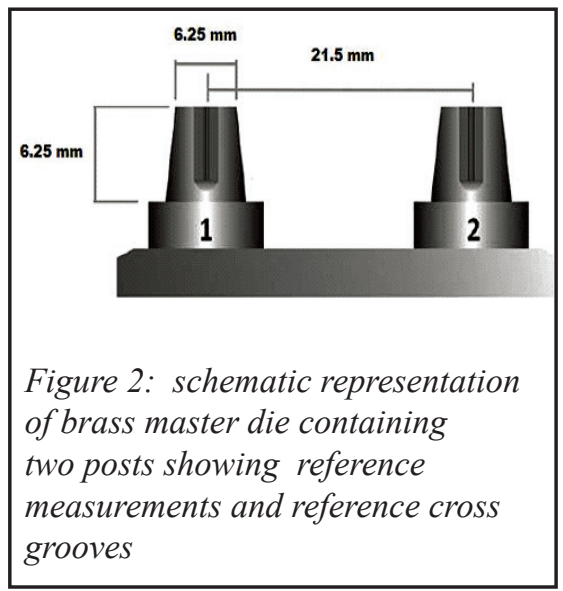

and allowed to dry for 15 minutes according to the manufacturer's recommendations. The monophase polyvinyl siloxane impression material was mixed using automix cartridge dispensing system. For the regular body polyvinyl siloxane impression material, equal amounts of both base and catalyst pastes were taken on mixing pad. The tray with the impression material was seated gently over the master model while maintaining the finger pressure until the material sets. The impression was allowed to set at room temperature as recommended by manufacturer. The impression was then removed with straight pull directed along the path of withdrawal of the preparations. The impression was checked for clinical acceptability.

Four different storage time intervals studied were 75 minutes, 24 hours, 48 hours and 1 week. 5 impressions of the master model were made for each impression material. Each impression was poured at four different storage time intervals studied. Thus a total of 20 impressions and 20 stone casts were obtained for each impression materials. Impressions were poured with type IV dental stone. To standardize the effect of the setting expansion of the improved stone, the water powder ratio was critically matched with manufacturer's recommendation and a product of similar batch number was used to pour all the impressions. Stone cast was removed from impression

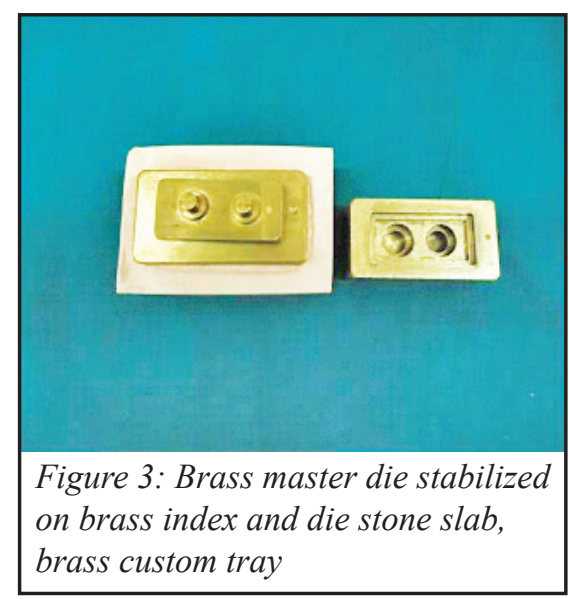




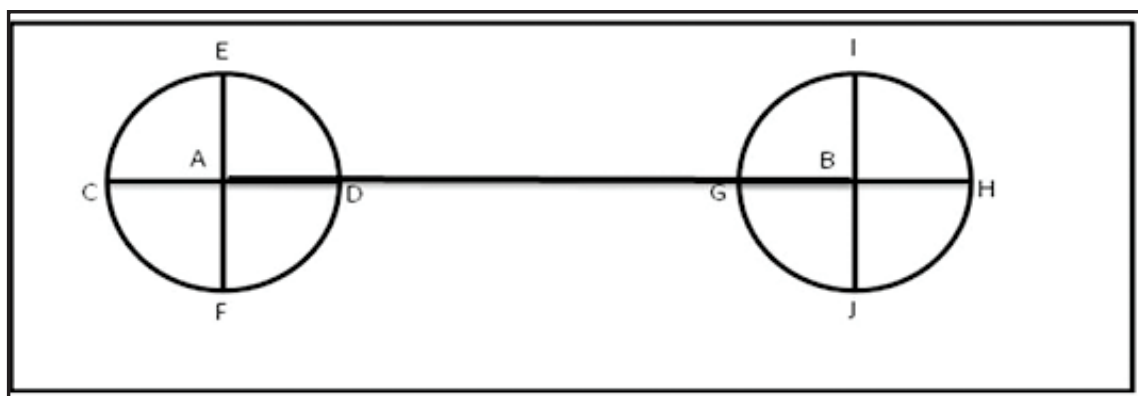

Figure 4: Reference points and linear dimensions measured

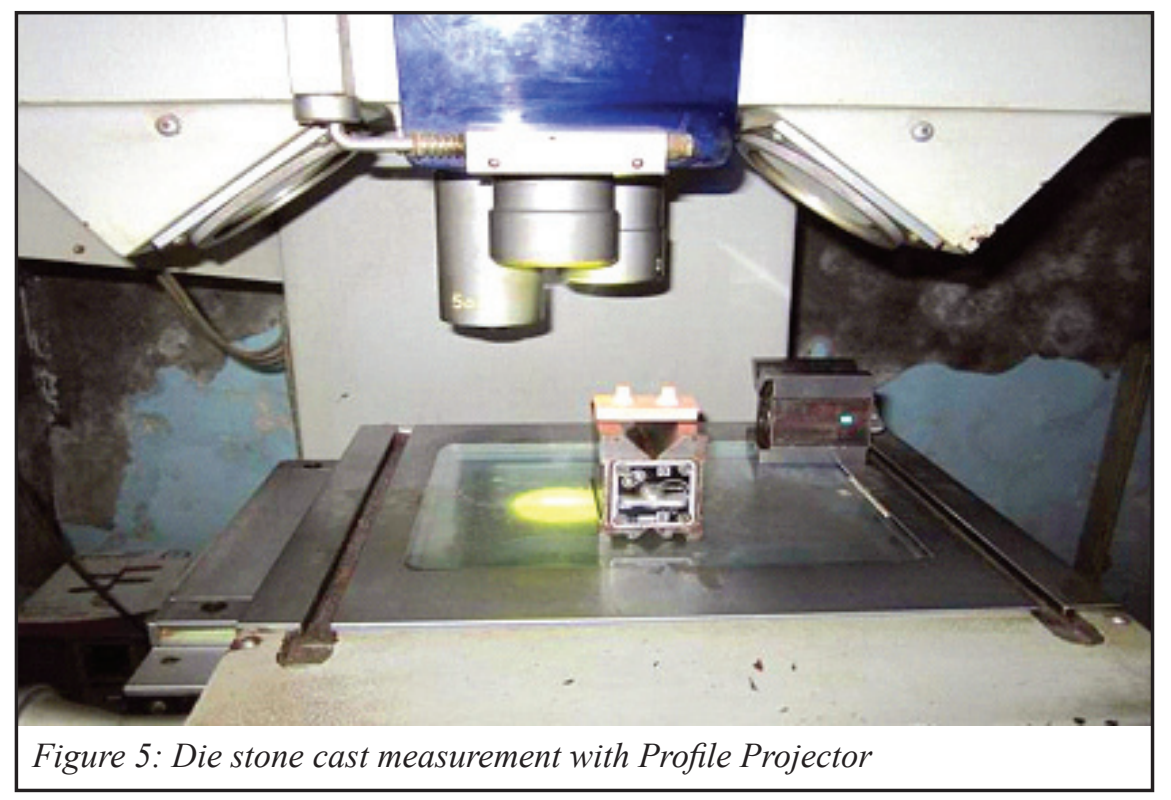

after 60 minutes to ensure complete setting of the stone.

\section{ASSESSMENT OF ACCURACY}

A profile projector with $\mathrm{x} 15$ magnification and accuracy of $0.001 \mathrm{~mm}$ or 1 um was utilized for the measurements of the stone casts. Interabutment (AB) and intraabutment (CD,EF, GH,IJ) dis- tances were measured. (Figure 4,5) and compared to master model. The data was subjected to statistical analysis.

\section{RESULTS}

Results of the study are shown in table 1 to 5 . Table 1 displays the absolute mean. Values of the inter-abutment distance $\mathrm{AB}$ and corresponding standard deviations. There was slight decrease in inter-abutment distance $(\mathrm{AB})$ as the time interval increased from $75 \mathrm{~min}$ to 1 week. Table 2 to 5 shows the absolute mean Values of the intra-abutment distance $\mathrm{CD}, \mathrm{EF}, \mathrm{GH}$ and IJ and their corresponding standard deviations. The intra-abutment distances $(C D$, $\mathrm{EF}, \mathrm{GH}$, and IJ) increased slightly as the time interval increased from 75 min to 1 week.

These results were analyzed for statistical comparison and significance by using one-way ANOVA Test. All of the deviations of the stone casts from the master model were within a clinically acceptable range(less than $90 \mathrm{um}$. The dimensions of stone casts made with both viscosities of addition silicone impression material i.e. monophase and regular body showed statiscally insignificant differences from the master model. The addition silicone impression materials were dimensionally stable for 1 week period

\section{DISCUSSION}

An accurate impression is the key to success of any restoration. An impression should reproduce hard and soft tissues around prepared and adjacent teeth in order to obtain biologically, mechanically, functionally and esthetically acceptable restorations. Accuracy of an impression depends on various factors such as impression material, impression technique used, type of impression trays, thickness of impression

\begin{tabular}{|c|c|c|c|c|c|c|c|}
\hline Group & Subgroups / Time Interval & $\mathbf{N}$ & Mean & Std. Deviation & Std. Error & Minimum & Maximum \\
\hline \multirow[t]{4}{*}{ A (Aquasil) } & A1 (75 Minutes) & 5 & 21.4558 & .074520 & .033326 & 21.361 & 21.547 \\
\hline & A2 (24 Hours) & 5 & 21.4389 & .124979 & .055892 & 21.310 & 21.589 \\
\hline & A3 (48 Hours) & 5 & 21.4249 & .144493 & .064619 & 21.247 & 21.589 \\
\hline & A4 (1 Week) & 5 & 21.3840 & .118013 & .052777 & 21.257 & 21.569 \\
\hline \multirow[t]{4}{*}{ B (Reprosil) } & A1 (75 Minutes) & 5 & 21.4430 & .090122 & .040304 & 21.313 & 21.567 \\
\hline & A2 (24 Hours) & 5 & 21.4374 & .080192 & .035863 & 21.343 & 21.565 \\
\hline & A3 (48 Hours) & 5 & 21.4174 & .089134 & .039862 & 21.329 & 21.529 \\
\hline & A4 (1 Week) & 5 & 21.3855 & .103536 & .046303 & 21.256 & 21.540 \\
\hline
\end{tabular}


Table 2: Mean and standard deviation values of intraabutment distance CD (in $\mathrm{mm}$ ) for each group at different time intervals for delayed pours

\begin{tabular}{llllllll} 
Group & Subgroups / Time Interval & $\mathbf{N}$ & Mean & Std. Deviation & Std. Error & Minimum & Maximum \\
\hline \multirow{2}{*}{ A (Aquasil) } & A1 (75 Minutes) & 5 & 6.2838 & .140448 & .062810 & 6.124 & 6.498 \\
\cline { 2 - 8 } & A2 (24 Hours) & 5 & 6.2956 & .088976 & .039791 & 6.155 & 6.399 \\
\cline { 2 - 8 } & A3 (48 Hours) & 5 & 6.3122 & .161480 & .072216 & 6.163 & 6.553 \\
\cline { 2 - 8 } & A4 (1 Week) & 5 & 6.3482 & .138361 & .061877 & 6.216 & 6.499 \\
\cline { 2 - 8 } & B1 (75 Minutes) & 5 & 6.2884 & .069755 & .031196 & 6.209 & 6.399 \\
\hline \multirow{2}{*}{ B (Reprosil) } & B2 (24 Hours) & 5 & 6.2928 & .104241 & .046618 & 6.132 & 6.411 \\
\cline { 2 - 8 } & B3 (48 Hours) & 5 & 6.3124 & .117428 & .052515 & 6.250 & 6.522 \\
\cline { 2 - 8 } & B4 (1 Week) & 5 & 6.3528 & .156193 & .069852 & 6.132 & 6.563
\end{tabular}

Table 3: Mean and standard deviation values of intraabutment distance EF (in $\mathrm{mm}$ ) for each group at different time intervals for delayed pours

\begin{tabular}{llllllll} 
Group & Subgroups / Time Interval & $\mathbf{N}$ & Mean & Std. Deviation & Std. Error & Minimum & Maximum \\
\hline A (Aquasil) & A1 (75 Minutes) & 5 & 6.2888 & .105068 & .046988 & 6.175 & 6.462 \\
\cline { 2 - 8 } & A2 (24 Hours) & 5 & 6.3218 & .111210 & .049735 & 6.139 & 6.443 \\
\cline { 2 - 8 } & A3 (48 Hours) & 5 & 6.3326 & .150887 & .067479 & 6.093 & 6.491 \\
\cline { 2 - 8 } & A4 (1 Week) & 5 & 6.3552 & .117961 & .052754 & 6.193 & 6.485 \\
\cline { 2 - 8 } & B1 (75 Minutes) & 5 & 6.2946 & .114633 & .051265 & 6.164 & 6.480 \\
\hline B (Reprosil) & B2 (24 Hours) & 5 & 6.3380 & .146062 & .065321 & 6.087 & 6.471 \\
\cline { 2 - 8 } & B3 (48 Hours) & 5 & 6.3428 & .135811 & .060737 & 6.100 & 6.410 \\
\cline { 2 - 8 } & B4 (1 Week) & 5 & 6.3646 & .172688 & .077229 & 6.067 & 6.471
\end{tabular}

Table 4: Mean and standard deviation values of intraabutment distance GH (in $\mathrm{mm}$ ) for each group at different time intervals for delayed pours

\begin{tabular}{llllllll} 
Group & Subgroups / Time Interval & $\mathbf{N}$ & Mean & Std. Deviation & Std. Error & Minimum & Maximum \\
\hline A (Aquasil) & A1 (75 Minutes) & 5 & 6.2663 & .076530 & .034225 & 6.130 & 6.305 \\
\cline { 2 - 8 } & A2 (24 Hours) & 5 & 6.2965 & .170506 & .076253 & 6.118 & 6.547 \\
\cline { 2 - 8 } & A3 (48 Hours) & 5 & 6.3106 & .114937 & .051401 & 6.145 & 6.451 \\
\cline { 2 - 8 } & A4 (1 Week) & 5 & 6.3753 & .177104 & .079203 & 6.072 & 6.482 \\
\cline { 2 - 8 } & B1 (75 Minutes) & 5 & 6.2682 & .095036 & .042502 & 6.115 & 6.345 \\
\hline B (Reprosil) & B2 (24 Hours) & 5 & 6.3175 & .131738 & .058915 & 6.145 & 6.449 \\
\cline { 2 - 8 } & B3 (48 Hours) & 5 & 6.3422 & .116037 & .051894 & 6.200 & 6.501 \\
\cline { 2 - 8 } & B4 (1 Week) & 5 & 6.3719 & .146284 & .065420 & 6.142 & 6.532
\end{tabular}

material, excessive seating pressure, too slow removal of impression from the mouth, storage conditions and stress relaxation.

An impression material is selected depending upon its dimensional accuracy, dimensional stability, working time, shelf life and electroplating capabilities etc. Addition silicone impression material i.e. polyvinyl siloxane is the most preferred material in the field of prosthodontics due to its favorable qualities as dimensional accuracy and stability, elastic recovery from undercuts, low creep and moderate to high tear resistance. However, Polyvinyl siloxane impression material may exhibit dimensional changes with delay in pouring due to continuing polymeriza- tion of the impression material, elastic recovery and relaxation of stresses (10). The results of the present study revealed that delayed pouring of impressions at different time intervals did not statistically significantly affect the dimensional accuracy of the casts produced from both viscosities of addition silicone impression material. The study also exhibited that there 


\begin{tabular}{|c|c|c|c|c|c|c|c|}
\hline Group & Subgroups / Time Interval & $\mathbf{N}$ & Mean & Std. Deviation & Std. Error & Minimum & Maximum \\
\hline \multirow[t]{4}{*}{ A (Aquasil) } & A1 (75 Minutes) & 5 & 6.2746 & .071423 & .031942 & 6.173 & 6.375 \\
\hline & A2 (24 Hours) & 5 & 6.2916 & .070365 & .031468 & 6.193 & 6.392 \\
\hline & A3 (48 Hours) & 5 & 6.3156 & .108790 & .048652 & 6.136 & 6.433 \\
\hline & A4 (1 Week) & 5 & 6.3548 & .115257 & .051545 & 6.194 & 6.497 \\
\hline \multirow[t]{4}{*}{ B (Reprosil) } & A1 (75 Minutes) & 5 & 6.2878 & .047262 & .021136 & 6.210 & 6.321 \\
\hline & A2 (24 Hours) & 5 & 6.3098 & .059630 & .026667 & 6.261 & 6.409 \\
\hline & A3 (48 Hours) & 5 & 6.3345 & .099298 & .044407 & 6.256 & 6.455 \\
\hline & A4 (1 Week) & 5 & 6.3654 & .112811 & .050451 & 6.229 & 6.507 \\
\hline
\end{tabular}

was slight decrease in interabutment distance whereas the intraabutment distances increased slightly as the time interval increased. The progressive increase or decrease in dimensions of stone casts as time interval increased was due to contraction of the impression material, but these changes were statistically insignificant. Similar results were obtained by William PT et al (11), Lacy AM et al (12), Eames et al (13), Ali KS and Shenoy VK (7), Marcinak CF and Draughn RA(14), Tjan AHL et al (15), Johnson GH and Craig RC (16), Thongthammachat et al (17).

However, the interabutment distance (AB) of the stone casts became continuously smaller when compared to the master model as the pouring time interval increased. The mean difference in interabutment distance for monophase addition silicone impression material ranged from $0.0442 \mathrm{~mm}$ $(0.2055 \%)$ at 75 minutes to $0.116 \mathrm{~mm}$ $(0.5395 \%)$ at 1 week whereas for regular body addition silicone impression the mean difference ranged from $0.057 \mathrm{~mm}$ $(0.2651 \%)$ at 75 minutes to $0.1144 \mathrm{~mm}$ $(0.5322 \%)$ at 1 week, maximum change being at 1 week for both materials. Ali KS and Shenoy VK (7), Marcinak CF and Draughn RA (14) and Tjan AHL et al (15) also observed similar results. This decrease in interabutment distance might be explained on the basis of pattern of polymerization shrinkage of the addition silicone impression material. During polymerization reaction, the impression material shrank towards the center of the mass or bulk of the material. However, the use of tray adhesive redirected the polymerization shrinkage towards the walls of the impression tray. So the impression material contracted towards the walls of the impression tray around each abutment. As there was bulk of impression material in between two abutments and also tray adhesive redirected the polymerization shrinkage towards the tray wall around each abutment, the position of midpoint of both abutments came closer i.e. interabutment distance decreased. Thermal contraction of the impression material, when the temperature was reduced from $370 \mathrm{C}$ to room temperature, could also have resulted in decrease in the interabutment distance.

The present study also indicated that the intraabutment distance for all stone casts became continuously larger than the master model. The mean difference in intraabutment distances for monophase addition silicone impression material ranged from $-0.0163 \mathrm{~mm}$ $(-0.2614 \%)$ to $-0.1253 \mathrm{~mm}(-2.005 \%)$ whereas for regular body addition silicone impression material the mean difference ranged from $-0.0182 \mathrm{~mm}$ $(-0.2918 \%)$ to $-0.122 \mathrm{~mm}(-1.951 \%)$, the greatest change being at 1 week for both materials. Johnson GH and Craig RC (16) and Thongthammachat et al (17) observed similar results.

This increase in intraabutment dis- tance observed may be due to the fact that impression material contracted towards the walls of the impression tray coated with tray adhesive. Polymerization shrinkage occurred towards the restrained surface (tray) and away from the unrestrained (tooth) surface. Furthermore, the greater contraction of the impression material towards the walls of the impression tray might have primarily affected the regions with smaller amount of the impression material per wall surface, such as in the areas surrounding the abutments. This might have resulted in increased intra-abutment distance or diameter of the abutments on the stone casts as compared to the master die (18).

The present study also exhibited that the deviations of the stone casts measurements from the master die were less than $90 \mathrm{um}$. It indicated that the deviations were within the limits of periodontal ligament space and hence clinically acceptable. The one way ANOVA analysis showed that this decrease in inter-abutment dimension and increase in intra-abutment dimensions with time for each addition silicone impression material was statistically insignificant $(\mathrm{p}>0.05)$. This implied that delayed pouring of impressions up to 1 week did not significantly affect the dimensional accuracy of the casts produced from both the viscosities of addition silicone impression materials evaluated. Thus impressions could be poured up to 1 week without undergo- 
ing any significant distortion.

Though the present study showed no statistically significant differences in the accuracy of casts obtained at different time intervals but there are various limitations of the study. As the study was carried out in-vitro, it did not take in to account the effect of various intraoral conditions such as the effect of oral fluids, soft tissues, different arch form and the effect of undercuts.

\section{CONCLUSION}

Within the limitations of this study, following conclusions were drawn:

- The dimensions of stone casts made with both viscosities of addition silicone impression material i.e. monophase and regular body showed statiscally insignificant differences from the master model for all storage time intervals i.e. 75 minutes, 24 hours, 48 hours and 1week.

- The interabutment distance decreased as the pouring time interval increased from 75 minutes to 1 week.

- The intraabutment distances increased as the pouring time interval increased from 75 minutes to 1 week.

- All of the deviations of the stone casts from the master model were within a clinically acceptable range(less than $90 \mathrm{um}$ ).

\section{REFERENCES}

1. Mishra S, Chowdhary R. Linear dimensional accuracy of a polyvinyl siloxane of varying viscosities using different impression techniques. Journal of Investigative and Clinical Dentistry 2010;1:37-46.

2. Nam J, Rajgrodski AJ, Townsend J, Lepe $X$, Mancl LA. Assessment of preference of mixing techniques and duration of mixing and tray loading for two viscosities of vinyl polysiloxane materials. J Prosthet Dent 2007;97:12-17.

3. Caputi S, Varvara G. Dimensional accuracy of resultant casts made by a monophase, one-step and two-step and a novel two-step putty/light-body impression technique: an invitro study. J Prosthet Dent 2008;99:274-81.

4. Yeh CL, Powers JM, Craig RG. Properties of addition type silicone impression materials. JADA 1980;101:482-84.

5. Shetty $P$, Rodrigues $S$. Accuracy of elastomeric impression materials on repeated pours. The Journal of Indian Prosthodontic Society 2006;6:68-71.

6. Morgano SM, Milot P, Ducharme P, Rose L. Ability of various impression materials to produce duplicate dies from successive impressions. J Prosthet Dent 1995; 73:333-40.

7. Ali KS, Shenoy VK, Rodrigues SJ. Comparative evaluation of dimensional accuracy of casts made by repeated pouring of addition silicone impressions using 1) Two-step putty/light body technique using stock tray and 2) one-step simultaneous dual viscosity technique using custom tray: An in-vitro study.J Nepal Dent Assoc 2010;11:32-39.

8. Stackhouse JA. The accuracy of stone dies made from rubber impression materials. $J$ Prosthet Dent 1970;24:377-86.

9. Tjan AHL, Whang SB, Tjan AH, Sarkissian R. Clinically oriented evaluation of the accuracy of commonly used impression materials. J Prosthet Dent 1986;56:4-8.
10. Revised American Dental Association Specification No. 19 for Non-Aqueous, Elastomeric Dental Impression Materials. JADA 1977;94:733-41.

11. Williams PT, Jackson DG, Bergman W. An evaluation of the time dependent dimensional stability of eleven elastomeric impression materials. J Prosthet Dent 1984;52:120-25.

12. Lacy AM, Fukui $H$, Bellman $T$, Jendresen MD. Time dependent accuracy of elastomer impression materials. Part II: Polyether, Polysulfids and polyvinyl siloxanes. J Prosthet Dent 1981;45:32933.

13. Eames WB, Wallace SW, Suway NB, Rogers LB. Accuracy and dimensional stability of elastomeric impression materials. J Prosthet Dent 1979;42:15962.

14. Marcinak CF, Draughn RA. Linear dimensional changes in addition curing silicone impression materials. $J$ Prosthet Dent 1982;47:411-13.

15. Tjan AHL, Whang SB, Tjan AH, Sarkissian R. Clinically oriented evaluation of the accuracy of commonly used impression materials. J Prosthet Dent 1986;56:4-8.

16. Johnson GH, Craig RG. Accuracy of four types of rubber impression materials compared with time of pour and a repeat pour of models. J Prosthet Dent 1985;53: 484-90.

17. Thongthammachat $S$, Moore BK, Barco MT, Hovijitra S, Brown DT, Andres CJ. Dimensional Accuracy of dental casts: Influence of tray material, impression material and time. J Prosthodont 2002;11: 98-108.

18. Tabreen A, Kumar S, Savadi RC. Evaluation and comparison of dimensional accuracy of different elastomeric impression materials under dry and wet conditions at various time intervals. Trends in Prosthodontics and Dental Implant logy 2010;1:31-33. 